\title{
MEMÓRIA GRÁFICA BRASILEIRA: Notícias de um campo em construção
}

\author{
Nadia Miranda Leschko \\ Pontifícia Universidade Católica do Rio de Janeiro \\ nadia.projeto@gmail.com \\ Vera Maria Marsicano Damazio \\ Pontifícia Universidade Católica do Rio de Janeiro \\ vdamazio@puc-rio.br \\ Edna Lúcia Oliveira da Cunha Lima \\ Pontifícia Universidade Católica do Rio de Janeiro \\ ednacunhalima@gmail.com \\ Joaquim Marçal Ferreira de Andrade \\ Pontifícia Universidade Católica do Rio de Janeiro \\ joaquim.marcal.andrade@gmail.com
}

Resumo: Este artigo apresenta marcos conceituais, teóricos e metodológicos do que vem se delineando como Memória Gráfica Brasileira e tem por finalidade contribuir para o desenvolvimento deste emergente campo de estudo. Ele foi baseado em dados obtidos por meio de entrevistas semi-estruturadas realizadas com pesquisadores de comprovada atuação na área - como os integrantes dos grupos de pesquisa "Memória Gráfica Brasileira: Estudos comparativos de manifestações gráficas nas cidades do Recife, Rio de Janeiro e São Paulo" (PROCADCAPES); "Núcleo de Identidade Gráfica Capixaba" da Universidade Federal do Espírito Santo e "Memória Gráfica de Pelotas: Um século de design", da Universidade Federal de Pelotas/RS - e está organizado em seções: a primeira descreve a metodologia, as questões guias aplicadas e os grupos de pesquisa definidos para esse estudo; a segunda apresenta o campo da memória gráfica brasileira, segundo os entrevistados; a terceira seus objetos de estudo; a quarta, seus principais métodos de pesquisa; a quinta, o referencial teórico.

Palavras-chave: Design Gráfico, Identidade, Cotidiano, Memória gráfica brasileira.

Abstract: This article presents conceptual, theoretical and methodological framework of an emerging field os studies that is being outlined as "Memória Gráfica Brasileira/Brazilian Graphic memory" and aims at contributing to its development. It was based on data collected through 
semi-structured interviews with researchers working in the field - as members of the following research groups: "Memória Gráfica Brasileira: Estudos comparativos de manifestações gráficas nas cidades do Recife, Rio de Janeiro e São Paulo" (PROCAD- CAPES); "Núcleo de Identidade Gráfica Capixaba" of the Federal University of Espírito Santo and "Memória Gráfica de Pelotas: Um século de design" of the Federal University of Pelotas - and is organized in sections; the first describes the methodology, the guiding questions and the research groups appointed for this study; the second presents the field of memória gráfica brasileira/Brazilian graphic memory, according to the researchers' interviews; the third, their objects of study; the fourth, their main research methods; the fifth, the theoretical framework.

Keywords: Graphic Design, Identity, Everyday, Brazilian graphic memory.

\section{INTRODUÇÃO}

O recente campo da Memória Gráfica Brasileira reúne um grupo de pesquisadores interessados em investigar a história e memória do design gráfico brasileiro, desvendando nomes, imagens, obras e aspectos sociais, técnicos e emocionais pouco conhecidos e até inéditos desta atividade.

Priscila Farias, integrante do projeto "Memória Gráfica Brasileira: Estudos comparativos de manifestações gráficas nas cidades do Recife, Rio de Janeiro e São Paulo", explica que o uso da terminologia "memória gráfica" é uma especificidade dos países de língua portuguesa e espanhola da América Latina, e refere-se "a uma linha de estudos que pretende revisar o significado e valor de artefatos visuais, e em particular os impressos efêmeros, para estabelecer uma noção de identidade local através do design" (FARIAS, 2014, p.1).

Assim, dentre as principais motivações deste grupo de pesquisadores, estão a afirmação de uma identidade para o design gráfico brasileiro através do inventário, análise e ações de preservação de artefatos gráficos. O conceito de gráfico, para o grupo, envolve uma gama de objetos que vão desde os impressos, passando por imagens que permeiam a paisagem urbana, até as relações afetivas desenvolvidas pelas pessoas para com estes artefatos.

A riqueza e amplitude das temáticas e objetos que são estudados sob esta denominação, envolvem perspectivas teóricas e metodológicas diferenciadas.

O objetivo deste texto é apresentar mapeamento dos principais aspectos relacionados aos processos de investigação adotados pelos membros da "Memória Gráfica Brasileira" com base na análise de entrevistas realizadas com pesquisadores do campo.

\section{METODOLOGIA}

O método adotado para a condução deste estudo foi o de entrevistas semiestruturadas com base em perguntas, cujo fim foi levar os entrevistados a uma reflexão sobre sua prática de pesquisa e descrição de seus principais conceitos, referencial teórico, métodos e motivações. As perguntas foram as seguintes:

1. O que é, para você, a memória gráfica brasileira? 
3. Quais são os projetos mais importantes que você realizou? Quais projetos você mais gostou de realizar?

2. O que motivou você a trabalhar nessa área?

4. Quais são os métodos que você utiliza? Qual o seu processo de pesquisa?

5. Quais referenciais teóricos que você utiliza?

6. Quais temas que você gostaria de investigar?

7. Em quais fóruns você divulga o seu trabalho?

8. O que você espera da Memória Gráfica Brasileira?

Foram selecionados para constituir o grupo de entrevistados, pesquisadores cujos currículos na Plataforma Lattes do CNPq traziam registros de participação em atividades de pesquisa relacionadas ao tema da "MGB", tendo sido grande parte deles integrantes dos grupos abaixo apresentados:

\title{
2.1. "Memória Gráfica Brasileira: Estudos comparativos de manifestações gráficas nas cidades do Recife, Rio de Janeiro e São Paulo" (PROCAD-CAPES)
}

O grupo foi formado em 2007 em virtude de edital Programa de Cooperação Acadêmica (PROCAD-CAPES) ${ }^{1}$ e reuniu 18 pesquisadores dos programas de pósgraduação em Design da PUC-Rio, Programa de Pós-Graduação em Design da UFPE e Programa de Pós-Graduação em Design do Centro Universitário Senac além de mestrandos, doutorandos e alunos de graduação bolsistas de iniciação à pesquisa das três instituições.

O resumo que consta da proposta de projeto contemplada do edital PROCADCAPES descreve que:

\begin{abstract}
O papel histórico e social do design no Brasil é assunto pouco estudado e compreendido, apesar de sua importância para a constituição da paisagem construída, para as diversas experiências de interação por meio do comércio e da comunicação, e para a formação de identidades visuais que, por extensão, ajudam a delimitar a identidade coletiva. $O$ presente projeto parte do pressuposto que 0 design precisa ser compreendido de modo integrado, como uma faceta do fenômeno maior da Cultura, no sentido antropológico desse termo. Ele tem, como objetivo principal, identificar e analisar exemplos relevantes de manifestações gráficas que marquem a memória, a paisagem urbana e a identidade das cidades do Rio de Janeiro, Recife e São Paulo (CARDOSO \& ALLIS, 2007, p.2).
\end{abstract}

Para o grupo, o design tem relação com a sociedade que o gera:

(...) desde os meandros da "cultura projetual" que rege a atuação de profissionais da área até os aspectos culturais mais abrangentes que governam a troca de bens materiais e simbólicos, o design não pode ser pensado à parte da comunidade em que é gerado e de suas relações subjacentes. (CARDOSO \& ALLIS, 2007, p.4).

Quanto ao campo da memória, é o primeiro aspecto a ser considerado, "tanto individual quanto coletiva", sendo imprescindível para compor qualquer campo de atuação. Diferente da história mas complementando-a, a memória "coloca-nos em contato direto com a noção de 'imaginação produtiva' ou 'instituição imaginária da

${ }^{1}$ O objetivo do PROCAD é "Promover a formação de recursos humanos de alto nível, nas diversas áreas do conhecimento, através de projetos conjuntos de pesquisa de média duração. Intensificar, também, o intercâmbio científico no país, por intermédio do envolvimento de equipes acadêmicas de diversas instituições de ensino superior e de pesquisa brasileiras, criando condições para a elevação geral da qualidade do ensino superior e da pós-graduação". Cfr em http://www.capes.gov.br/bolsas/programas-especiais/procad 
sociedade', nos termos cunhados pelo filósofo Cornelius Castoriadis" (CARDOSO \& ALLIS, 2007, p.4). Para Marques dos Santos (apud CARDOSO \& ALLIS, 2007, p.4) "a memória é um fenômeno sempre atual, na qual o passado, mais que reconstituído, é reconstruído num plano afetivo e mágico".

Assim, em qualquer atividade que envolva a criação, a memória é fundamental para análise do exercício da mesma.

Ainda referenciando memória, é citado Maurice Halbwachs que trata da mesma como fenômeno consciente, coletivo e intencional, conforme seu livro "A Memória Coletiva". "Vivemos e lembramos em sociedade e dentro de um entorno material" (CARDOSO \& ALLIS, 2007, p.4). Não podemos separar as imagens do mundo exterior do nosso eu, elas são parte de nossa identidade, afirma o autor.

Manifestações gráficas como embalagens, cartazes, letreiros, livros, cardápios, passagens, bilhetes, diplomas, etc, participam do nosso cotidiano, tornando-se suportes de memória e

(...) ilustram uma das mais bem sucedidas relações entre as pessoas e o meio projetado e apresentam uma perspectiva inédita para o entendimento de nossa sociedade e desenvolvimento de produtos com foco na promoção de experiências memoráveis e sentimentos positivos (CARDOSO \& ALLIS, 2007, p.4).

Ainda segundo o projeto de pesquisa, o adjetivo "gráfico", acompanhado à memória, delimita um campo de estudos. A produção gráfica, para a área do design, está relacionada à evolução da impressão tipográfica (século XV) e transformações tecnológicas e comerciais que vieram com o surgimento de uma indústria gráfica (século XIX)

Ampliando o conceito,

(...) o fazer gráfico diz respeito a toda forma de expressão que envolva o registro e a difusão de informações verbais e visuais por meio de tecnologias de multiplicação e meios de comunicação. Nessa acepção mais ampla - seguindo da idéia de "programação" do mundo, defendida pelo filósofo Vilém Flusser (FLUSSER APUD CARDOSO \& ALLIS, 2007, p.4) -, o termo pode abarcar desde o desenho de tipos até os atuais sistemas de mídias digitais (CARDOSO \& ALLIS, 2007, p.4).

O grupo também delimita os estudos à esfera nacional, à experiência brasileira. Parte-se do princípio de que a identidade brasileira é uma construção histórica que merece estudos mais aprofundados "que ajude a compreender a natureza e as funções de sua continuada formação" (CARDOSO \& ALLIS, 2007, p.5).

Os objetivos gerais do grupo tal qual apresentado no projeto são:

- Investigar a história do design gráfico no Brasil;

- Estudar a relação afetiva do indivíduo com o meio gráfico;

- Identificar e analisar manifestações gráficas que marquem a memória, a paisagem urbana e a identidade das cidades do Rio de Janeiro, Recife e São Paulo;

- Estudar as coincidências e dissonâncias entre manifestações gráficas similares presentes nas três cidades;

- Desenvolver e aprimorar metodologias de pesquisa para o estudo destas manifestações gráficas;

- Chegar a resultados que possam ser utilizados como parâmetros para a avaliação e preservação destas manifestações gráficas enquanto parte de nosso patrimônio histórico, artístico e cultural. 


\section{2 "Núcleo de Identidade Gráfica Capixaba" (Nigráfica) do Estado do Espírito Santo}

O Núcleo de Identidade Gráfica Capixaba (Nigráfica) foi criado em 2009 e está vinculado ao Laboratório de Design: História e Tipografia do curso de Desenho Industrial da Universidade Federal do Espírito Santo - UFES e reúne 11 pesquisadores.

A missão do grupo é

(...) através do levantamento e análise de impressos produzidos no Espírito Santo, identificar o que seria característico da identidade gráfica capixaba. Esta pesquisa se insere no âmbito das pesquisas na área do design que lidam com a memória gráfica brasileira ${ }^{2}$.

O grupo parte do pressuposto que muitos designers e pesquisadores tem se ocupado a fazer estudos em tipografia, rótulos, jornais, revistas com objetivo de delimitar a cultura material no âmbito da identidade brasileira. O que o Nigráfica propõe é estudar o caso específico da formação gráfica do Espírito Santo. Para tanto, são estudados os acervos da Biblioteca Estadual e Arquivo Público.

Entre as pesquisas desenvolvidas e finalizadas pelo grupo estão "Identidade Gráfica Capixaba" cujo objeto foram as revistas periódicas "Vida Capixaba" e "Instituto Histórico e Geográfico do Espírito Santo" do período compreendido entre 1910 e 2010. Foi realizado levantamento, registro e digitalização dessas revistas pertencentes ao acervo da Biblioteca Pública do Espírito Santo.

O projeto "Artes gráficas do IFES" investigou o curso de Tipografia e Encadernação da antiga Escola Técnica Federal do Espírito Santo. Foram relacionadas a estrutura e metodologia do ensino das artes gráficas na escola bem como a importância para a formação dos profissionais da área.

Entre os projetos em andamento estão "Tecnologia Gráfica Capixaba" que visa relacionar conhecimentos acerca do parque gráfico e aparelhamento no Estado do Espírito Santo e "Identidade Gráfica Capixaba - análise e memória gráfica". Este último projeto tem duas frentes: nova análise, mais aprofundada, das revistas "Vida Capixaba" e "Instituto Histórico e Geográfico do Espírito Santo" levando em conta aspectos da linguagem visual (tipografia, diagramação, ilustração, anúncios, formato, uso de cores, etc) bem como influências culturais, econômicas, sociais, políticas e tecnológicas. Outro ramo do projeto se dedica à análise da "Revista Capixaba", no mesmos moldes das revistas já mencionadas.

\section{3 "Memória Gráfica de Pelotas: Um século de design", de Pelotas/RS}

O grupo de pesquisa Memória Gráfica de Pelotas foi concebido em 2005 a partir da constatação da existência de material que apontou indícios de uma tradição gráfica em Pelotas/RS. O grupo está vinculado ao curso de Design Gráfico da Universidade Federal de Pelotas e possui 10 integrantes.

Os primeiros estudos basearam-se no acervo de rótulos das indústrias conserveiras de Pelotas, buscando dar visibilidade à produção local desse tipo de impresso e, com isso, fazer um levantamento das técnicas de impressão utilizadas pelas indústrias locais na primeira metade do século XX. A proposta inicial evoluiu culminando no projeto "Memória Gráfica de Pelotas: um século de design", financiado pela FAPERGS (Fundação de amparo à pesquisa do Estado do Rio Grande do Sul) no

\footnotetext{
${ }^{2}$ LadHT. Laboratório de Design: História e Tipografia.

Disponível em: <https://www.facebook.com/pages/LadHT/103751353058974?id=103751353058974\&sk=info> Acesso em 10 mai.2014
} 
período de Junho/2010 a julho/2012. Os estudos foram desenvolvidos na Bibliotheca Pública Pelotense, concentrados na análise do "Almanach de Pelotas" e edições comemorativas do jornal "Diário Popular". Nesta fase, o grupo se propôs a identificar, categorizar e analisar os objetos citados, com base em critérios definidos como eixos temáticos de produção, além de promover ações de conservação e preservação, inventariando e digitalizando o acervo selecionado com vistas a formar uma base de dados a ser disponibilizada a outros pesquisadores em meio virtual.

Os objetivos do grupo Memória Gráfica de Pelotas são:

- Investigar e aplicar procedimentos para catalogar, indexar e duplicar o Acervo de Periódicos (Design Editorial) do Acervo da Bibliotheca Pública Pelotense;

- Produzir, registrar e publicar conhecimentos acerca da memória e da identidade visual local, revertendo o quadro de ausência e/ou deficiência em relação a fontes de pesquisa e documentação sobre os processos de produção e execução do design local;

- Identificar possibilidades projetuais a partir da utilização de métodos tradicionais em projetos contemporâneos.

Além dos 39 integrantes dos grupos acima apresentados, integram o grupo de selecionados para as entrevistas 10 pesquisadores em um total de 49 . Os dados apresentados a seguir foram extraídos de 10 entrevistas realizadas ao longo do 2 은 semestre de 2013.

\section{SOBRE MEMÓRIA GRÁFICA BRASILEIRA}

Perguntar para os entrevistados o que é Memória Gráfica Brasileira foi um exercício bastante rico e variado. As respostas não estavam prontas e não vieram fáceis. Cada pesquisador tentou formular um conceito próprio de acordo com o desenvolvimento do seu trabalho. Ao analisar as respostas, verificou-se que houve quem associasse o conceito de Memória Gráfica Brasileira à história, como ilustram as passagens abaixo:

(...) memória gráfica brasileira está mais relacionado a essa questão de resgate, de ocorrências gráficas, nas quais a gente pode perceber uma história.

(...) tenho trabalhado memória gráfica como um aspecto daquilo que vamos chamar de História do Design Gráfico.

(...) entendo [a MGB] como algo que pode ser história, algo ligado à história, (...) mas também entendo que aí tem um conceito muito mais amplo.

A relação entre memória e história é um tema complexo, cabendo compartilhar, de forma sucinta, a distinção entre os dois conceitos proposta pelo sociólogo Maurice Halbwachs (1990) que apoiará nossas reflexões.

Para o importante autor do campo dos Estudos da Memória, memória e história se opõem em vários pontos: a história reúne acontecimentos que não assistimos, mas 
conhecemos por meio da leitura ou conversação. Ela diz respeito àquilo que podemos imaginar, mas não podemos lembrar. A memória, por sua vez, diz respeito a acontecimentos dos quais participamos e são parte de nossa trajetória de vida. Ela apóia-se na história e é influenciada pela atmosfera psicológica e social de um dado tempo, lugar e circunstâncias políticas e nacionais, mas é interior e pessoal. A memória processa-se em grupo e encontra suporte nas memórias dos outros, havendo tantas memórias quantos forem os grupos dos quais participamos. Portanto, é preciso haver pessoas para que a memória esteja presente.

Já a história, é "a compilação dos fatos que ocuparam o maior espaço na memória dos homens". Esses fatos são ensinados nas escolas, estão presentes nos livros e foram selecionados conforme "necessidades ou regras que não se impunham aos círculos de homens que deles guardaram por muito tempo a lembrança viva". A história, para Halbwachs, começaria no momento em que cessam as tradições. Ressaltando a distinção entre memória e história, o autor explica ainda que enquanto uma lembrança existe, "é inútil fixá-la por escrito, nem mesmo fixá-la, pura e simplesmente" (HALBWACHS, 1990, p. 80).

Voltando às respostas de nossos entrevistados, verificou-se que pesquisadores que relacionaram a Memória Gráfica Brasileira à história, se valem de recursos metodológicos próprios dos estudos de memória como levantamento dos acontecimentos vividos, como entrevistas e histórias de vida para melhor compreensão de seus objetos de pesquisa. Outros entrevistados associaram a MGB ao universo gráfico diretamente relacionado a acontecimentos vividos e à memória tal qual definida por Maurice Halbwachs, como ilustra o depoimento a seguir:

Resumindo memória gráfica brasileira tem muito a ver com a vida de pessoas em solo brasileiro e as experiências mediadas por objetos gráficos. Biscoito Globo, picolé Dragão Chinês, praia, domingo de sol, cartas do Mico Preto, tabuleiro de War, casa da avó, brincadeira com os primos, figurinhas do sabonete Eucalol, álbuns da seleção brasileira, o Brasil que pára na frente da TV durante as copas... Isso é memória gráfica brasileira para mim.

Os estudos desta pesquisadora são conduzidos com base em impressos como embalagens e ingressos e são as lembranças evocadas, as experiências afetivas vividas e os significados atribuídos às manifestações gráficas que constituem seu objeto de trabalho. Essa forma de trabalho é a que mais se aproxima do conceito de memória proposto por Halbwachs.

Em algumas respostas, observou-se que o conceito de Memória Gráfica Brasileira foi diretamente associado à natureza dos objetos das investigações dos entrevistados. Em uma delas, a MGB é definida como "todo o material impresso desde que há imprensa no Brasil" até aos dias de hoje, destacando os impressos efêmeros como jornais, revistas e rótulos. Em outra resposta "é tudo que se produziu nesse país, embora, na historiografia consideramos que só dá para estudar memória gráfica brasileira a partir da transferência da sede da Corte para o Rio de Janeiro, em 1808, quando começa a impressão régia".

De acordo com o conceito de história em Halbwachs, os depoimentos acima dizem respeito ao que poderíamos definir como "história de objetos gráficos", pois trata-se de suportes de acontecimentos de tempos distantes. Para estudá-los, não é 
possível se recorrer às pessoas que guardam lembranças destes objetos ou viveram experiências mediadas pelos mesmos.

Observamos, então, que há pesquisadores que se aproximam sua definição ao conceito de memória e outros ao conceito de história do design gráfico e que tanto um como o outro estão abrigados pelo nome Memória Gráfica Brasileira.

\section{SOBRE OS OBJETOS DE ESTUDO DA MEMÓRIA GRÁFICA BRASILEIRA}

Ao contrário do observado na questão anterior, os entrevistados sentiram-se mais à vontade quando indagados acerca de seus objetos de estudo.

As respostas foram formuladas mais prontamente e apresentaram diversidade de objetos associados ao universo gráfico brasileiro.

Alguns entrevistados não se detiveram somente à descrição de seus objetos de pesquisa, mas lembraram a importância de se contextualizar os mesmos na época em que foram produzidos e/ou utilizados. Fundamentando este ponto, uma das pesquisadoras lembra que "um projeto de design não é descolado do seu tempo ou do contexto em que foi produzido". Esta é uma noção de objeto que vai além da análise gráfica e colabora para compor um panorama social, econômico e político do tempo e para a construção de uma história contada a partir dos objetos.

A preocupação com a contextualização está presente nas falas de outros entrevistados que trabalham com objetos efêmeros:

(...) o que mais me interessa dentro da memória gráfica são os impressos efêmeros e nesse pacote entram jornais, revistas, rótulos (...) o livro se pensa para a eternidade, é feito para uma durabilidade maior. O efêmero não, ele é feito para ser jogado fora no dia seguinte e é isso que eu acho fascinante (...) eu comparo muito com o retrato posado e o instantâneo: o livro é um retrato posado, as pessoas sentadinhas ali sorrindo tal como querem figurar para a posteridade, o que é muito interessante. Os outros são instantâneos e ninguém está preocupado com o que vai acontecer dali há 100 anos.

A pesquisadora faz uso de uma metáfora para definir o que é objeto perene e objeto efêmero e o potencial do último de revelar informações sobre o cotidiano de uma época e o modo como as pessoas viviam em tempos pretéritos.

Vale ressaltar que a maior parte dos pesquisadores trabalha com objetos efêmeros, como rótulos, embalagens, jornais e revistas. A riqueza dos efêmeros é exemplarmente ilustrada na explanação da pesquisadora a respeito dos objetos que a instiga:

O que eu tenho é uma abundância de objetos gráficos que geralmente são objetos anônimos como o jornal. Quem é que faz um jornal? Quem é que fez o projeto do jornal? Quem trabalhou no jornal? Na verdade, a parte gráfica do jornal é escondida através do texto. Se você for ver o trabalho da história da imprensa, ele nunca fala do impressor, ou do compositor, da pessoa que trabalhou na parte de mecânica para fazer o objeto virar aquilo que ele é. Geralmente ele fala do texto, do escritor, no sentido de redator, da pessoa que escreve e nunca da refeição gráfica que o jornal tem e que é tão marcante. 
Aqueles que investigam os objetos efêmeros frequentemente se deparam com a falta de autoria dos responsáveis por seus projetos. Esse é outro desafio que os entrevistados têm de enfrentar. Muitas vezes um produto gráfico apresenta características marcantes e torna-se um ícone para o público, mas seu idealizador e criador não é identificado. Para contornar essa situação, os pesquisadores recorrem ao entorno do objeto, o meio produtivo, o uso dado ao produto, além de peças similares para reconstruir as relações do objeto com seu tempo e local.

\section{MÉTODOS DE PESQUISA DA MEMÓRIA GRÁFICA BRASILEIRA}

Esse foi outro tópico no qual os entrevistados pensaram um pouco antes de responder. Parte deles afirmou que a primeira etapa costuma ser dedicada à procura de objetos nos acervos e que o estudo toma forma quando "coisas" relevantes são encontradas. Em geral, a temática de pesquisa vem depois de descoberto o objeto.

Tal como descrevem alguns entrevistados:

(...) vamos atrás, tentamos encontrar as coisas. Nós temos a sorte de termos acervos muito interessantes aqui na cidade.

A primeira coisa é você olhar, "chafurdar", ver que tipo de material tem, porque tem acervos que só tem revistas; outros têm fotografia, revista, áudio, vídeo e muita mídia.

Outra etapa apontada como importante diz respeito à definição do recorte:

Tem que identificar o acervo e identificar qual é a amostragem (...) não tinha como eu analisar 60 anos de um jornal diário, olhar cada edição, então defini uma amostragem e quais os itens seriam analisados.

A elaboração de fichas de análise também foi destacada pelos entrevistados como importante suporte sobretudo para a realização de análises comparativas.

Eu parto muito dessa função de análise de fichas, de tabelas; e também me interessa essa questão comparativa, sempre comparar com alguma coisa (...)

De acordo com alguns entrevistados, fichas bem elaboradas permitem verificar recorrências e dissonâncias entre os objetos gráficos, enriquecendo a análise.

Enquanto alguns pesquisadores "chafurdam" e "vão atrás das coisas" em acervos, outros preferem "abrir gavetas" e conversar sobre seus guardados:

O meu método para estudar a Memória Gráfica Brasileira começaria, por exemplo, em um prédio de Copacabana bem variado e o pedido para seus moradores abrirem suas gavetas. O que você guardou aí? Há muitas lembranças e histórias guardadas em gavetas sob a forma de artefatos gráficos.

Conversar sobre acervos foi apontado como método por mais entrevistados. Isso quando as pessoas que guardam vínculos com os objetos estudados ainda estão vivas. Um entrevistado disse que na falta dos autores do design procura conversar com 
quem está relacionado de alguma forma com o objeto. Essas pessoas podem ser os detentores da coleção de objetos ou gestores dos acervos que tenham conhecimentos acerca da origem dos mesmos. A partir dos depoimentos colhidos, o pesquisador pode identificar dados sobre o contexto desse objeto: como foi produzido, quem é o autor, quando foi produzido, como o público recebeu esse produto. Parte-se, então, para a pesquisa bibliográfica com o intuito de descobrir se há algum escrito sobre o produto, o autor ou mesmo o contexto da época em que foi produzido.

Em resumo, os principais métodos levantados pelos entrevistados foram busca por objetos nos acervos, amostragem, fichamento e entrevistas com pessoas ligadas aos objetos.

\section{REFERENCIAL TEÓRICO}

As respostas variaram bastante e alguns entrevistados citaram outros pesquisadores do grupo como referência.

O brasileiro mais citado pelos entrevistados foi Rafael Cardoso, historiador do design, autor de livros importantes como "Uma introdução à história do design", a coletânea "O design brasileiro antes do design", "Design para um mundo complexo" entre outras contribuições. É importante ressaltar que Cardoso foi o coordenador geral do grupo de pesquisa "Memória Gráfica Brasileira: Estudos comparativos de manifestações gráficas nas cidades do Recife, Rio de Janeiro e São Paulo" nos dois primeiros anos do projeto. Uma das suas maiores contribuições foi lançar olhar para objetos que não eram considerados parte do universo do design, como os artefatos do cotidiano que passaram despercebidos nos livros de história do design. Também apontou novos caminhos para a pesquisa em história do design em geral e do design gráfico em particular. Na introdução da coletânea "O design brasileiro antes do design", Cardoso explica que "perdura na consciência nacional o mito de que o design brasileiro teve sua gênese por volta de 1960" (CARDOSO, 2005, p.7). Segundo o autor, o que aconteceu foi uma ruptura no qual surgiu "não o design propriamente dito - ou seja, as atividades projetuais relacionadas à produção e ao consumo em escala industrial -, mas antes a consciência do design como conceito, profissão e ideologia" (CARDOSO, 2005, p.7). Cardoso cita alguns marcos para a mítica gênese do design no Brasil, como a abertura do Instituto de Arte Contemporânea do MASP, em 1951, e a inauguração da Escola Superior de Desenho Industrial (ESDI) em 1963. O autor defende haver muita produção que pode ser considerada design muito antes desses marcos. Os textos dessa coletânea corroboram para essa afirmação e a contribuição foi, entre outras, conferir moldura a peças gráficas e objetos que, segundo o movimento vigente, não seriam considerados design.

Dentre os autores brasileiros, foram citados também Orlando da Costa Ferreira, autor de "Imagem e letra", importante obra sobre a história e a técnica da imagem gravada no país e Frederico Porta, autor de "Dicionário de Artes Gráficas" editado pela extinta Livraria do Globo de Porto Alegre. Ainda que sua última edição tenha saído em 1958, esse dicionário permanece sendo um importante referencial sobre a história da produção gráfica.

Um dos pesquisadores citou o antropólogo e escritor político brasileiro Darcy Ribeiro como referencial, sendo um autor que versa sobre história do Brasil. Assim, o entrevistado amplia a gama de referências teóricas para além dos autores comumente citados. 
Dentre os autores do campo dos Estudos da Memória, foram apontados os autores Maurice Halbwachs, acima apresentado, além de Henri Bergson, filósofo francês conhecido pelo seu ensaio "Matéria e Memória", e Joël Candau, professor de antropologia da Universidade de Nice na França e autor de "Memória e Identidade".

\section{CONSIDERAÇÕES FINAIS}

$O$ estudo que deu origem a este artigo está em andamento e incluirá dados de entrevistas com mais 10 pesquisadores, assim como análise e cruzamento mais detalhados de todas as respostas.

Podemos afirmar, contudo, que a Memória Gráfica Brasileira é um campo em construção vasto e de alicerces sólidos.

Todos entrevistados ressaltaram a riqueza e variedade do acervo que ainda está para ser estudado e explorado. Muitos valorizaram ainda as coisas simples do cotidiano e sua estreita relação com a identidade brasileira. Discorrendo sobre a forte associação do design com glamour, uma das pesquisadoras lembrou que:

(...) existe um mundo de objetos gráficos que não são propriamente chiques. São coisas simples do cotidiano e que certamente fazem parte daquilo que é ser brasileiro. É no cotidiano que o design se faz presente das formas mais diversas e variadas. E é na simplicidade dos objetos do dia a dia que se encerra a essência de uma sociedade.

As manifestações gráficas do cotidiano se mostraram concorridos objetos de pesquisa deste emergente campo de estudo. Para uma das entrevistadas, objetos simples como embalagens de doce e rótulos de cachaça, são como retratos da vida cotidiana e revelam muito mais do que os livros podem contar.

Esta idéia ganhou contornos no "museu da memória gráfica virtual", imaginado por outra pesquisadora, cujo acervo seria constituído por objetos comuns de pessoas comuns e as histórias de vida que eles revelam.

Podemos afirmar, finalmente, que a julgar pela variedade, qualidade e quantidade de objetos para estudar, o vasto e novo campo da Memória Gráfica Brasileira terá vida longa e um futuro promissor.

\section{REFERÊNCIAS}

CARDOSO, Rafael. 0 design brasileiro antes do design: aspectos da história gráfica, 1870-1960. Org. Rafael Cardoso. São Paulo: Cosac Naify, 2005.

CARDOSO \& ALLIS. Projeto de pesquisa PROCAD Memória Gráfica Brasileira: Estudos comparativos de manifestações gráficas nas cidades do Recife, Rio de Janeiro e São Paulo, 2007.

Desenvolvimento da "Ficha de Coleta de Dados" para análise gráfica da revista Vida Capichaba. Disponível em:

<http://blogs.anhembi.br/congressodesign/anais/artigos/69536.pdf> Acesso em 22 abr.2014 
FARIAS, Priscila Lena. On graphic memory as a strategy for design history. In: International Committee for Design History and Design Studies, Aveiro, Portugal, 2014.

HALBWACHS, Maurice. A Memória Coletiva. Tradução de Laurent Léon Schaffter. São Paulo: Edições Vértice, 1990.

LadHT. Laboratório de Design: História e Tipografia. Disponível em:

<https://www.facebook.com/pages/LadHT/103751353058974?id=103751353058974

\&sk=info> Acesso em 10 mai.2014

Memória Gráfica de Pelotas. Disponível em:

<www2.ufpel.edu.br/iad/memoriagraficadepelotas/sobre.html>

Acesso em 22 abr.2014

PPGI - Projeto de pesquisa: Identidade Gráfica Capixaba. Disponível em:

<http://portais.ufes.br/PRPPG/ext/projetos.php?prog=30001013007P0\&cdproj=1167> Acesso em 22 abr.2014 